\title{
Polycyclic aromatic hydrocarbons in soils from the Central-Himalaya region: Distribution, sources, and risks to humans and wildlife
}

Xiang Bi a,b,1, Wei Luo a,*,1, Jiajia Gao a,i ${ }^{\text {a, }}{ }^{\text {Lan }} \mathrm{Xu}^{\mathrm{a}}$, Junming Guo ${ }^{\mathrm{c}}$, Qianggong Zhang ${ }^{\mathrm{c}, \mathrm{d}}$, Kumar Y. Romesh ${ }^{\mathrm{e}}$, John P. Giesy ${ }^{\text {f }}$, Shichang Kang ${ }^{\text {g,d }}$, Jacob de Boer ${ }^{\mathrm{h}}$

a State Key Laboratory of Urban and Regional Ecology, Research Center for Eco-Environmental Sciences, Chinese Academy of Sciences, Beijing 100085, China

${ }^{\mathrm{b}}$ Graduate University of Chinese Academy of Sciences, China

c Key Laboratory of Tibetan Environment Changes and Land Surface Processes, Institute of Tibetan Plateau Research, Chinese Academy of Sciences (CAS), Beijing 100085, China

' CAS Center for Excellence in Tibetan Plateau Earth Sciences, Chinese Academy of Sciences, Beijing 100101, China

e Department of Environmental Science and Engineering, School of Science, Kathmandu University, Kathmandu 6250, Nepal

${ }^{\mathrm{f}}$ Department of Veterinary Biomedical Sciences and Toxicology Centre, University of Saskatchewan, Saskatoon, Canada

' State Key Laboratory of Cryospheric Sciences, Cold and Arid Regions Environmental and Engineering Research Institute, Chinese Academy of Sciences, Lanzhou 730000, China

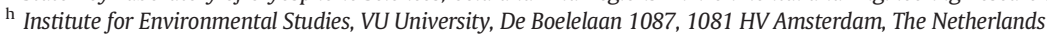

${ }^{i}$ Tibet Climatic Center, Lhasa 850001, China

\section{H I G H L I G H T S}

- PAH concentrations in soils were presented in a unique area of the Himalayas.

- Altitude was a significant factor controlling PAHs in mountain soils.

- Sources of PAHs in soils were identified by positive matrix factorization analysis.

- $39 \%$ of soils had a slight risk to wildlife and environment of the Central Himalayas.

\section{GRA P H ICA L A B S T R A C T}

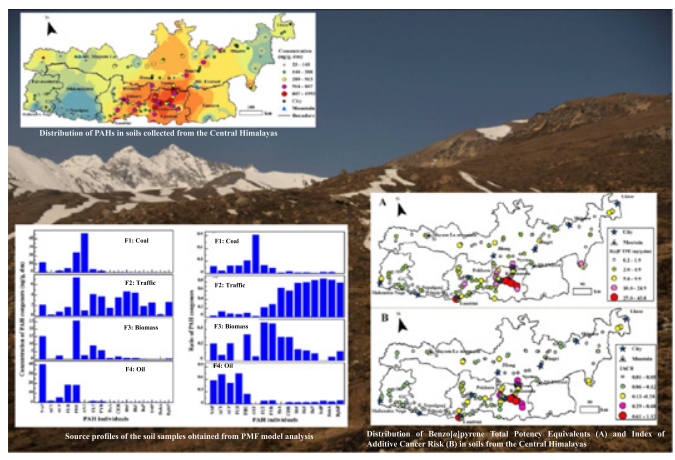

\section{A R T I C L E I N F O}

\section{Article history:}

Received 29 November 2015

Received in revised form 2 March 2016

Accepted 2 March 2016

Available online 11 March 2016

Editor: F. Riget

\section{Keywords:}

Tibetan Plateau

Nepal

China

\begin{abstract}
A B S T R A C T
The Central Himalayas are not only a natural boundary between China and Nepal but also a natural barrier for transport of air masses from South Asia. In this study, 99 samples of surface soil were collected from five regions of Nepal on the southern side of the Central Himalayas, and 65 samples of surface soil were obtained from the northern side on the edge of the Tibetan Plateau, China (TPC). Concentrations of polycyclic aromatic hydrocarbons (PAHs) in soils were measured to determine their distribution, potential for accumulation, and sources, as well as risks to humans and the environment. Mean concentrations of $\Sigma_{16}$ PAHs were $2.4 \times 10^{2}$ and $3.3 \times 10^{2} \mathrm{ng} / \mathrm{g}$ dry mass $(\mathrm{dm})$ in soils collected from the TPC and Nepal, respectively. Significant correlations between concentrations of lower molecular weight PAHs (LMW-PAHs) in soils and altitude were found. Total organic carbon (TOC) in soil was positively but weakly correlated with concentrations of PAHs in the study area, which suggested little role of TOC in adsorption of PAHs. The cities of Kathmandu and Pokhara in Nepal and Nyemo (especially Zhangmu Port), Shigatse, and Lhasa on the TPC, were areas with relatively great
\end{abstract}

\footnotetext{
* Corresponding author.

E-mail address: luow@rcees.ac.cn (W. Luo).

1 Wei Luo and Xiang Bi contributed equally to this work.
} 
PMF model

Toxicity assessment

Mountain concentrations of PAHs in soils. The main sources of PAHs identified by positive matrix factorization were emissions from motor vehicles and combustion of coal and biomass in the Central Himalayas. Calculated total benzo[a]pyrene potency equivalents of $0.23-44 \mathrm{ng} / \mathrm{g} \mathrm{dm}$ and index of additive cancer risk of $3.8 \times 10^{-3}-$ $9.2 \times 10^{-1}$ indicated that PAHs in almost all soils investigated posed de minimis risk of additional cancer to residents via direct contact and had no significant risk of additional cancers through consumption of potable water. Mean risk quotient values indicated that $39 \%$ of soils had a slight risk to wildlife and the ambient environment of the Central Himalayas.

(c) 2016 Elsevier B.V. All rights reserved.

\section{Introduction}

Polycyclic aromatic hydrocarbons (PAHs) are a group of pollutants that are widely distributed, persistent and toxic and have potential for bioaccumulation. They can migrate to remote alpine regions via longrange, atmospheric transport (LRAT) and be deposited in environments due to orographic, cold-trapping effects (Choi et al., 2009; Wania and Westgate, 2008). Accumulation of PAHs in cold environments might affect alpine ecosystems or pose risks to health of people relying on alpine ecosystems for food and water (Vives et al., 2004; Fernández et al., 2002).

In terrestrial environments, soils act as a sink for PAHs. More than 90\% of the total mass of PAHs in the environment is stored in soils (Wild and Jones, 1995). In warmer climates, soil can contribute PAHs to the atmosphere (Dalla Valle et al., 2005). PAHs in soils might be further deposited on or accumulated into vegetables or other biota via food chains (Li et al., 2008). Further, leaching of PAHs from soils can contaminate groundwater (Bortey-Sam et al., 2014). Therefore, monitoring concentrations of PAHs in soils is important for assessing their potential effects on the environment or humans.

Investigation of patterns of accumulation of PAHs along altitudinal gradients can elucidate factors affecting their fates in mountainous environments. The Central Himalayas are a geographical zone separating India, Pakistan, and Nepal in South Asia from China. The Tibetan plateau, China (TPC) is at the northern side of the Central Himalayas, and it is also an important source of water for surrounding regions. Although local emissions of PAHs in the TPC are limited, it is surrounded by the most densely populated and rapidly industrializing countries such as India and China. Emission of $\Sigma$ PAHs in China was estimated to be 25,300 tons in 2003. China and India had the greatest emissions of PAHs to the atmosphere in 2004 (Xu et al., 2006; Zhang and Tao, 2009). During the Indian monsoon, PAHs are transported and deposited to various environmental matrices, including soil, grass, snow and ice, and sediments on the TPC (Wang et al., 2007; Wang et al., 2008; Wang et al., 2010; Li et al., 2011). In recent years, emissions of PAHs in Nepal have increased due to growth of local population as well as development of highways and additional usage of motor vehicles. Furthermore, valleys of the Himalayas in Nepal are channels for transport of PAHs from the Indian subcontinent to the TPC (Yang et al., 1987). Thus, the Himalayas are considered to be an ideal region for investigating the LRAT of PAHs. Thus far, few studies have investigated emissions of PAHs from the Central Himalayas (Aichner et al., 2007; Guzzella et al., 2011; Chen et al., 2015).

Investigations of spatial distribution and sources of PAHs in soils from the Central-Himalaya region are important for understanding cross-border migration of PAHs between South Asia and the TPC, factors influencing accumulation of PAHs, and assessment of their potential effects on health people residing in this relatively pristine area. In this study, concentrations of 16 indicator PAHs specified by the US Environmental Protection Agency (EPA) were measured in 164 samples of soil collected from both sides of the Central Himalayas on the TPC and in Nepal. The information was used to determine the potential sources of PAHs, the factors influencing their accumulation, as well as risks for humans and the environment.

\section{Materials and methods}

\subsection{Collection of samples}

Distribution of PAHs in Nepal was determined by collecting samples of soil along a West-to-East transect. Soils were also collected from the TPC, where PAHs might be transported via monsoon and atmospheric circulations and (Fig. 1). Nine samples of soil from a subarea in farwestern Nepal mountain area where, as suggested by Wang et al. (2014), sparse PAHs emission and human activities existed, were selected to investigate effects of altitude on accumulation of PAHs in soils (Table 1 and Fig. 1B). The climate in the studied regions is dominated alternatively by the Indian monsoon and westerly winds (Wang et al., 2013). In total, 164 soil samples (99 from Nepal and 65 from the TPC) were collected from remote sites (i.e., away from towns, roads, or other human activities) on the two sides of the Himalayas between 2013 and 2014, using a stainless steel spade (Fig. 1). Among soils from Nepal, 36, 27, 17, 17, and 2 samples of soil were collected from the central, western, mid-western, far-western, and eastern parts of Nepal, respectively. Newly fallen leaves were discarded before soils were collected. Three or four surface samples $(0-5 \mathrm{~cm})$ were obtained over an area of approximately $100 \mathrm{~m}^{2}$ from each part, and then composited to form a representative sample of soil. Samples were wrapped in aluminum foil, kept in the dark, and transported to the laboratory and maintained at $-20^{\circ} \mathrm{C}$.

\subsection{Sample extraction and analysis}

Soils were air-dried, sieved through 2-mm mesh, and spiked with chemical surrogates (four deuterated PAHs, i.e., naphthalene-d8 (NAP$\mathrm{d} 8$ ), acenaphthene-d10 (ACP-d10), phenanthrene-d10 (PHE-d10), and chrysene-d12 (CHR-d12)) for calculating recoveries. Next, 16 PAHs, including naphthalene (NAP), acenaphthylene (ACY), acenaphthene (ACP), fluorene (FLR), phenanthrene (PHE), anthracene (ANT), fluoranthene (FLT), pyrene (PYR), benz $[a]$ anthracene (BaA), chrysene (CHR), benz $[b]$ fluoranthene $(\mathrm{BbF})$, benz[ $k]$ fluoranthene $(\mathrm{BkF})$, benzo[a]pyrene (BaP), indeno[1,2,3-cd]pyrene (IcdP), dibenz[ $a, h]$ anthracene (DahA), and benzo[ghi]perylene (BghiP), were identified and quantified using an Agilent 6890 gas chromatograph equipped with a HP-5MS capillary column ( $30 \mathrm{~m} \times 0.25 \mathrm{~mm}$ i.d $\times 0.25 \mu \mathrm{m}$ film thickness) for separation and an Agilent 5975 mass spectrometer with an electron impact ionization source as a detector. Further information about the extraction and analysis methods is provided in Text SI-1. Samples of soils were treated with $1 \mathrm{~mol} / \mathrm{L} \mathrm{HCl}$ to remove inorganic carbon. Subsequently, they were cleaned with Milli-Q water until neutral pH $(7 \pm 0.2)$ and dried at $80^{\circ} \mathrm{C}$. The determination of total organic carbon (TOC) was performed by flash combustion at $1025{ }^{\circ} \mathrm{C}$ followed by thermal conductivity detection in a Vario TOC. The limit of detection was $0.1 \%$.

\subsection{Quality assurance/quality control}

Interferences were checked by analyzing cross-contamination and stability of the instrument during the entire analytical process, procedural blanks, and spiked blank samples with each block of 10 samples. 

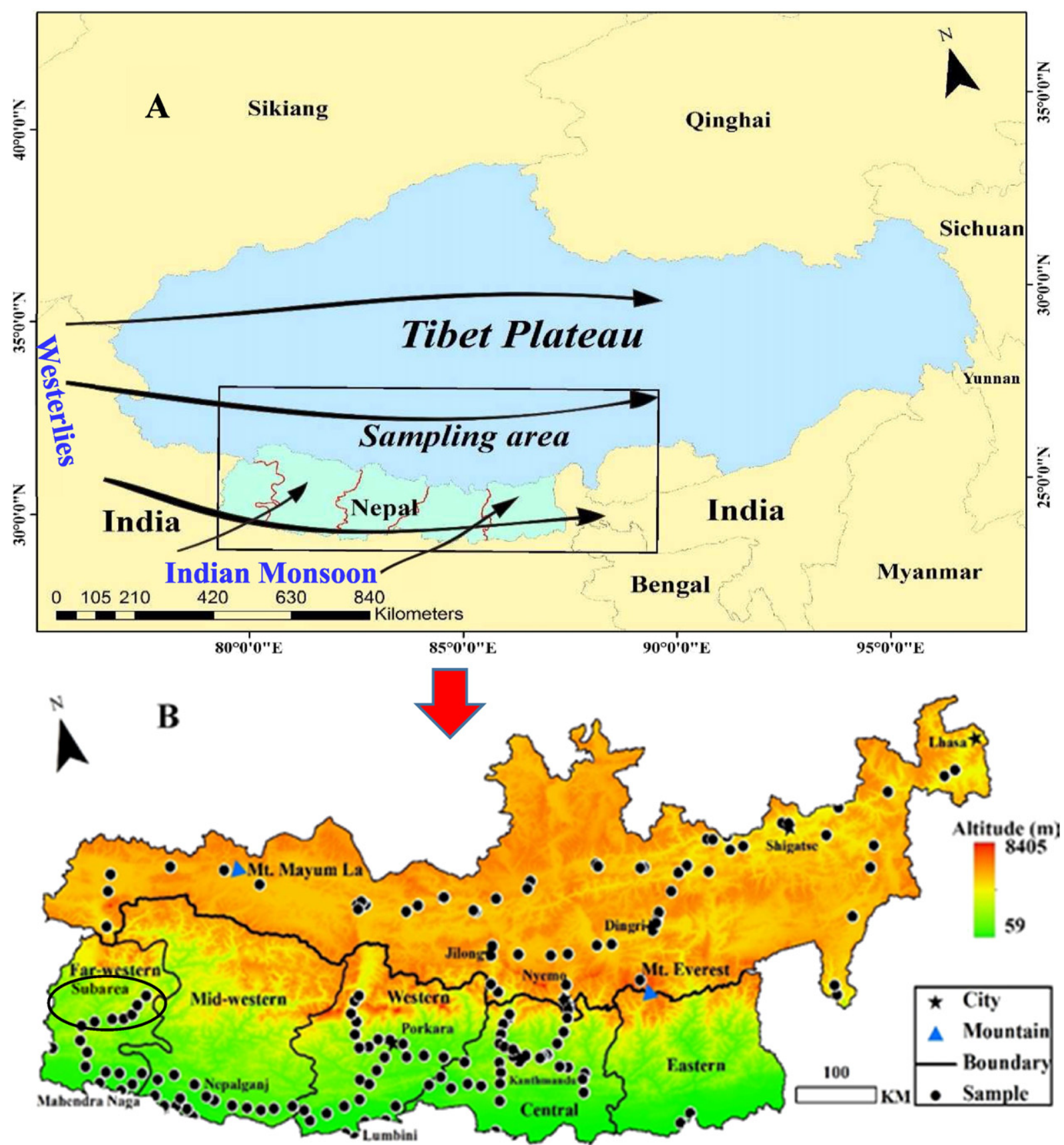

Fig. 1. General pattern of atmospheric circulation systems (A) and map of soil sampling sites (B) in the Central Himalayas. Soil sampling subarea is identified by a black ellipse.

Table 1

Description of soil samples in a subarea and concentrations of individual PAHs (ng/g dm) in the Central Himalayas.

\begin{tabular}{|c|c|c|c|c|c|c|c|}
\hline ID & Latitude $\left({ }^{\circ} \mathrm{N}\right)$ & Longitude $\left({ }^{\circ} \mathrm{E}\right)$ & Altitude (m) & LMW-PAHs ${ }^{\mathrm{a}}$ & 4-ring PAHs & HMW-PAHs ${ }^{\mathrm{b}}$ & PAHs \\
\hline 1 & 29.01 & 80.63 & 1521 & 43 & 9.6 & 2.9 & 56 \\
\hline 2 & 29.15 & 80.59 & 1793 & $2.0 \times 10^{2}$ & 30 & 13 & $2.4 \times 10^{2}$ \\
\hline 3 & 29.29 & 80.64 & 1665 & $1.2 \times 10^{2}$ & 20 & 10 & $1.5 \times 10^{2}$ \\
\hline 4 & 29.30 & 80.79 & 608 & 23 & 6.6 & 3.0 & 33 \\
\hline 5 & 29.27 & 81.00 & 1464 & 90 & 19 & 7.5 & $1.2 \times 10^{2}$ \\
\hline 6 & 29.24 & 81.12 & 1697 & $2.0 \times 10^{2}$ & 20 & 6.5 & $2.2 \times 10^{2}$ \\
\hline 7 & 29.26 & 81.22 & 690 & 44 & 14 & 6.2 & 64 \\
\hline 8 & 29.34 & 81.31 & 1138 & 60 & 16 & 13 & 90 \\
\hline 9 & 29.41 & 81.43 & 1127 & $1.2 \times 10^{2}$ & 21 & 16 & $1.6 \times 10^{2}$ \\
\hline Mean & 29.25 & 80.97 & 1300 & 99 & 17 & 8.7 & $1.3 \times 10^{2}$ \\
\hline
\end{tabular}

\footnotetext{
a Low molecular weight PAHs (2-3 ring PAHs).
}

b High molecular weight PAHs (5-6 ring PAHs). 
Mean concentration of $\Sigma$ PAHs in the procedural blank was $1.2 \mathrm{ng} / \mathrm{g}$ dry mass $(\mathrm{dm})$. The predominant PAH was naphthalene (NAP). Recoveries from spiked blanks were $70 \%-106 \%$. Mean recoveries of the spiked surrogates in all samples were $68 \%-136 \%$ for the four deuterated PAHs. The method detection limits (MDLs), defined as 3 times of signal-to-noise value, were $0.4-7.2 \mathrm{ng} / \mathrm{g} \mathrm{dm}$ for PAHs. The performance of the instrument was routinely checked using quality control standards.

\subsection{Positive matrix factorization analysis}

Positive matrix factorization (PMF) was used for assessment of potential sources of PAHs. The principles and usage of the PMF 5.0 model are described in detail in the user manual (http://www.epa.gov/ heasd/documents/PMF_5.0_User_Guide.pdf). Input data for the model require two input files: one for the measured concentrations (C) of PAHs and the other for the estimated uncertainty (U) associated with those concentrations. In the file containing concentrations, a surrogate value equivalent to half the MDL was substituted for samples for which the concentration was less than the MDL. The input matrix of uncertainties was calculated using the MDL for each species and measurement uncertainty (MU, \%). If the concentration was less than the MDL, then $U=5 / 6 \mathrm{MDL}$, otherwise $\mathrm{U}=\left[(\mathrm{MU} \times \mathrm{C})^{2}+(\mathrm{MDL})^{2}\right]^{1 / 2}$. The procedure was performed following guidelines specified in the user manual. The number of factors in the PMF model was selected based on closeness of a robust $\mathrm{Q}$ value (robust $\mathrm{Q}$ is the goodness-of-fit parameter calculated excluding outliers) to the theoretical $\mathrm{Q}$ value (theoretical $\mathrm{Q}=$ $\mathrm{nm}$ for a small data set, where $\mathrm{n}=$ number of samples, $\mathrm{m}=$ number of variables), the diagnostic plots, and the relevance of the resolved factors to known physical sources (Wang et al., 2015).

\subsection{Environmental and human health risk assessment}

The Canadian Soil Quality Guidelines for protection of environmental and human health were used for screening-level risk assessment (http://ceqg-rcqe.ccme.ca/download/en/320). Factor assessment of human health protection from direct contact with PAH-contaminated soil was calculated as benzo[a]pyrene total potency equivalents $(\mathrm{B}[\mathrm{a}] \mathrm{P}$ TPEs). To estimate B[ $a]$ P TPEs, each PAH was assigned a carcinogenic potential, and equivalency factors (EFs) were used to quantify carcinogenic potencies of the remaining PAHs relative to BaP. The list of EFs (Table 2) compiled previously (Tsai et al., 2004) was adopted to calculate the $\mathrm{B}[\mathrm{a}] \mathrm{P}$ TPEs. Therefore, the toxic equivalent (based on carcinogenicity) of each individual $\mathrm{PAH}$ was obtained by multiplying its concentration with the appropriate $\mathrm{EF}$, i.e., $\mathrm{B}[a] \mathrm{P}$ TPE $=\Sigma\left(\mathrm{C}_{\mathrm{i}} \times \mathrm{EF}_{\mathrm{i}}\right)$. The human health soil quality guidelines $\left(\mathrm{SQG}_{\mathrm{HH}} \mathrm{S}\right)$ for carcinogenic contaminants require development of soil quality guidelines that employ a critical risk-specific dose, based on incremental lifetime cancer risks (ILCRs) from exposure to PAHs in soil. Adult humans were considered as receptors when considering lifetime cancer risk. For nonthreshold contaminants, exposure of humans needs to be reduced to the maximum extent possible. $\mathrm{SQG}_{\mathrm{HH}} \mathrm{S}$ were calculated based on $10^{-6}$ ILCR.

The index of additive cancer risk (IACR) assesses potential risk posed by drinking groundwater due to leaching of carcinogenic mixtures of PAHs from soil. The IACR is calculated by dividing the concentration of each carcinogenic PAH by its SQG value for the protection of potable water component value and summing these hazard subindices for the entire PAH mixture (Eq. (1)).

$$
\begin{aligned}
& I A C R=\frac{B a A}{0.33 \mathrm{mg} \mathrm{kg}^{-1}}+\frac{B[b+k] F}{0.16 \mathrm{mg} \mathrm{kg}^{-1}}+\frac{B g h i P}{6.8 \mathrm{mg} \mathrm{kg}^{-1}} \\
& +\frac{B a P}{0.37 \mathrm{mg} \mathrm{kg}^{-1}}+\frac{\mathrm{Chr}}{2.1 \mathrm{mg} \mathrm{kg}^{-1}}+\frac{\text { DahA }}{0.23 \mathrm{mg} \mathrm{kg}^{-1}}+\frac{I c d P}{2.7 \mathrm{mg} \mathrm{kg}^{-1}}
\end{aligned}
$$

For protection of the environment and wildlife, PAHs were individually compared to SQGs, which were developed based on noncarcinogenic effects. Since the mean risk quotient ( $m$-RQ) could reduce a large amount of chemical data into a single number for mixtures of contaminants (McCready et al., 2006; Wang et al., 2015), the m-RQ was used to assess combined ecological risks of target PAHs in Central Himalayan soils. Based on the SQGs of 11 PAHs (ANT, BaP, FLT, NAP, PHE, BaA, BbF, BkF, DahA, IcdP, and PYR), the m-RQ was calculated by dividing the concentration of each individual $\mathrm{PAH}$ by its respective midrange SQG, summing the quotients, and dividing by the total number of all individual PAHs.

\subsection{Air mass trajectory calculation}

Backward extrapolations of trajectories of air masses were developed to probe the potential sources of PAHs. Two sites $\left(28.1^{\circ} \mathrm{N}, 84.4^{\circ}\right.$ $\mathrm{E} ; 29.2^{\circ} \mathrm{N}, 86.0^{\circ} \mathrm{E}$ ) at the centers of the Nepal and the study area in the TPC were selected as starting points (Fig. S2). Ten-day backward trajectories starting at $1000 \mathrm{~m}$ above the ground were calculated using HYSPLIT 4 with NCAR/NCEP re-analysis global meteorological data at 24 h intervals for 10 years from January 1, 2003 to December 31, 2012 to represent the air circulation in this area in general. The calculated trajectories for each sub-area were clustered into 5 or 6 categories with the total spatial variance below $30 \%$.

\subsection{Statistical analyses and geographic information system mapping}

Data were checked to see if they met assumptions of homogeneity of variance and normality (Kolmogorov-Smirnov test). Differences in concentrations of PAHs between the TPC and Nepal were compared using one-way analysis of variance, followed by least significant difference test. Statistical analyses were performed using SPSS for Windows version 20.0 (IBM, USA). A $p$ value of $<0.05$ was considered statistically significant. Geographical information system (GIS) coordinates and concentrations of PAHs in surface soils obtained from the CentralHimalaya region were used to create distribution maps. Concentrations of PAHs in the soils were interpolated by the inverse distance weighting method provided by Geostatistical Analyst in ArcGIS software (ver. 10.0, ESRI, USA).

\section{Results and discussion}

\subsection{Concentrations of PAHs}

Concentrations of $\Sigma_{16} \mathrm{PAHs}$ in soils of the Central Himalayas ranged from 23 to $1.6 \times 10^{3} \mathrm{ng} / \mathrm{g} \mathrm{dm}$, with a mean of $3.0 \times 10^{2} \mathrm{ng} / \mathrm{g} \mathrm{dm}$. Mean concentration of $\Sigma_{16}$ PAHs in soils of Nepal $\left(3.3 \times 10^{2} \mathrm{ng} / \mathrm{g} \mathrm{dm}\right)$ was significantly higher than that in soils of the TPC $\left(2.4 \times 10^{2} \mathrm{ng} /\right.$ $\mathrm{g} \mathrm{dm} ; p<0.05)$. Furthermore, mean concentrations of 2-3-ring PAHs (low-molecular-weight PAHs (LMW-PAHs)) and 4-ring PAHs, as well as 5-6-ring PAHs (high-molecular-weight PAHs (HMW-PAHs)) in soils of Nepal were greater than those in soils of the TPC $(p<0.05)$. LMW-PAHs were the dominant PAHs, accounting for $81 \%$ and $79 \%$ of the mean concentrations of PAHs in soils of the TPC and Nepal, respectively. In all studied soils, the most abundant PAH was PHE (26\%), followed by NAP (24\%) and ANT (17\%) (Table 2).

The mean concentration of $\Sigma_{16} \mathrm{PAHs}$ in soils of the CentralHimalayas region was greater than those in soils of Changbai Mountain and mountains of Western Canada, but less than those in soils of European mountain areas and subtropical Atlantic areas (Ribes et al., 2003a; Choi et al., 2009; Quiroz et al., 2010; Zhao et al., 2015) (Table S1). Unlike that in other studies conducted in Nepal, the mean concentration of $\Sigma_{16} \mathrm{PAHs}$ in soils of Nepal was greater than that in soils of Sagarmatha National Park, but less than that in soils of Kathmandu (Aichner et al., 2007; Guzzella et al., 2011), as well as Agra, Delhi, Kurukshetra, and other cities located in the north of India 
Table 2

Concentrations and soil quality guidelines (SQGs) (ng/g dm) of PAHs in surface soils from the Central-Himalaya region (ng/g dm).

\begin{tabular}{|c|c|c|c|c|c|c|c|c|c|c|c|c|}
\hline \multirow[t]{2}{*}{ Compounds } & \multirow[t]{2}{*}{ No. of ring } & \multirow[t]{2}{*}{$\mathrm{EF}^{\mathrm{a}}$} & \multirow[t]{2}{*}{$\mathrm{SQGS}^{\mathrm{b}}$} & \multicolumn{3}{|c|}{ Tibetan Plateau, China $(n=65)$} & \multicolumn{3}{|l|}{ Nepal $(n=99)$} & \multicolumn{3}{|l|}{ Total $(n=164)$} \\
\hline & & & & Min-Max & Mean \pm SD & $\operatorname{Abs}^{c}(\%)$ & Min-Max & Mean \pm SD & Abs (\%) & Min-Max & Mean \pm SD & Abs (\%) \\
\hline NAP & 2 & 0.001 & 600 & $5.7-6.7 \times 10^{2}$ & $55 \pm 90$ & 23 & $5.0-4.5 \times 10^{2}$ & $79 \pm 92$ & 24 & $5.1-6.7 \times 10^{2}$ & $70 \pm 91$ & 24 \\
\hline ACY & 3 & 0.001 & 320,000 & $0.091-8.3$ & $1.9 \pm 2.1$ & 0.78 & $0.11-12$ & $2.6 \pm 2.7$ & 0.80 & $0.091-12$ & $2.3 \pm 2.5$ & 0.79 \\
\hline ACP & 3 & 0.001 & 280 & $1.3-59$ & $8.7 \pm 9.9$ & 3.7 & $1.8-50$ & $12 \pm 9.4$ & 3.6 & $1.3-59$ & $10 \pm 9.7$ & 3.7 \\
\hline FLR & 3 & 0.001 & 250 & $0.33-1.1 \times 10^{2}$ & $21 \pm 23$ & 8.7 & $0.13-1.3 \times 10^{2}$ & $28 \pm 30$ & 8.5 & $0.13-1.3 \times 10^{2}$ & $25 \pm 27$ & 8.6 \\
\hline PHE & 3 & 0.001 & 100 & $8.4-267$ & $64 \pm 54$ & 27 & $6.3-3.8 \times 10^{2}$ & $82 \pm 81$ & 25 & $6.3-3.8 \times 10^{2}$ & $75 \pm 71$ & 26 \\
\hline ANT & 3 & 0.01 & 2500 & $0.38-3.2 \times 10^{2}$ & $43 \pm 74$ & 18 & $0.45-4.5 \times 10^{2}$ & $54 \pm 97$ & 17 & $0.38-4.5 \times 10^{2}$ & $50 \pm 88$ & 17 \\
\hline FLT & 4 & 0.001 & 50,000 & $1.9-67$ & $16 \pm 12$ & 6.6 & $1.7-1.2 \times 10^{2}$ & $20 \pm 21$ & 6.2 & $1.7-1.2 \times 10^{2}$ & $19 \pm 17$ & 6.3 \\
\hline PYR & 4 & 0.001 & 100 & $1.1-45$ & $10 \pm 8.4$ & 4.3 & $1.2-73$ & $14 \pm 14$ & 4.2 & $1.1-73$ & $13 \pm 12$ & 4.3 \\
\hline $\mathrm{BaA}$ & 4 & 0.1 & 100 & $0.16-9.8$ & $1.4 \pm 1.7$ & 0.61 & $0.24-25$ & $2.8 \pm 4.2$ & 0.87 & $0.16-25$ & $2.4 \pm 3.6$ & 0.81 \\
\hline CHR & 4 & 0.01 & & $0.62-47$ & $4.6 \pm 6.7$ & 1.9 & $0.73-33$ & $6.5 \pm 7.6$ & 2.0 & $0.62-47$ & $5.9 \pm 7.5$ & 2.0 \\
\hline $\mathrm{BbF}$ & 5 & 0.1 & 100 & $0.26-55$ & $3.9 \pm 7.5$ & 1.7 & $0.33-69$ & $7.0 \pm 11$ & 2.1 & $0.26-69$ & $6.0 \pm 10$ & 2.1 \\
\hline $\mathrm{BkF}$ & 5 & 0.1 & 100 & $0.16-50$ & $3.4 \pm 6.7$ & 1.4 & $0.28-62$ & $6.5 \pm 11$ & 2.0 & $0.16-62$ & $5.6 \pm 9.8$ & 1.9 \\
\hline $\mathrm{BaP}$ & 5 & 1 & 20,000 & $0.048-13$ & $1.4 \pm 2.4$ & 0.57 & $0.073-21$ & $2.6 \pm 4.6$ & 0.80 & $0.048-21$ & $2.2 \pm 3.9$ & 0.75 \\
\hline IcdP & 6 & 0.1 & 100 & $0.0056-17$ & $1.8 \pm 3.2$ & 0.76 & $0.041-30$ & $3.5 \pm 6.2$ & 1.1 & $0.0056-30$ & $2.9 \pm 5.3$ & 0.99 \\
\hline DahA & 6 & 1 & 100 & $0.0024-2.6$ & $0.26 \pm 0.46$ & 0.11 & $0.0017-4.6$ & $0.49 \pm 0.92$ & 0.15 & $0.0017-4.6$ & $0.42 \pm 0.78$ & 0.14 \\
\hline BghiP & 6 & 0.01 & & $0.053-17$ & $2.0 \pm 3.4$ & 0.83 & $0.061-32$ & $4.1 \pm 6.6$ & 1.3 & $0.053-32$ & $3.4 \pm 5.7$ & 1.12 \\
\hline LMW-PAHs & & & & $19-1.4 \times 10^{3}$ & $2.0 \times 10^{2} \pm 2.3 \times 10^{2}$ & 82 & $17-1.3 \times 10^{3}$ & $2.6 \times 10^{2} \pm 2.9 \times 10^{2}$ & 79 & $17-1.4 \times 10^{3}$ & $2.3 \times 10^{2} \pm 2.6 \times 10^{2}$ & 80 \\
\hline 4-ring PAHs & & & & $3.8-1.7 \times 10^{2}$ & $32 \pm 28$ & 13 & $3.9-2.1 \times 10^{2}$ & $43 \pm 44$ & 13 & $3.8-2.1 \times 10^{2}$ & $40 \pm 39$ & 13 \\
\hline HMW-PAHs & & & & $0.61-1.3 \times 10^{2}$ & $13 \pm 22$ & 5 & $0.86-2.2 \times 10^{2}$ & $24 \pm 39$ & 8 & $0.61-2.2 \times 10^{2}$ & $21 \pm 34$ & 7 \\
\hline$\Sigma_{16}$ PAHs & & & & $27-1.6 \times 10^{3}$ & $2.4 \times 10^{2} \pm 2.5 \times 10^{2}$ & 100 & $23-1.5 \times 10^{3}$ & $3.3 \times 10^{2} \pm 3.3 \times 10^{2}$ & 100 & $23-1.6 \times 10^{3}$ & $3.0 \times 10^{2} \pm 3.0 \times 10^{2}$ & 100 \\
\hline
\end{tabular}

a Equivalency factors.

b Canadian soil quality guidelines (SQGs) (ng/g, dm) for the protection of environmental and human health.

c Abundance. 
(Masih and Taneja, 2006; Agarwal et al., 2009; Kumar et al., 2013). These results indicated that sources of PAHs might be present in the vicinity of the area. In this study, the mean concentration of $\Sigma_{16} \mathrm{PAHs}$ in soils of the TPC was approximately 3 -fold greater than region background concentrations for the Qinghai-Tibetan Plateau (Tao et al., 2011; Wang et al., 2013), but similar to those in the southeastern TPC, which is considered to receive PAH input via the Indian monsoon (271 ng/g dm) (Yang et al., 2013).

The pattern of concentrations of $\Sigma_{16}$ PAHs in soils from the study area was significantly different from that in other areas affected by human activities, such as the traffic-affected and coal-related area of Dalian and densely populated area in Agra, where 4-ring and HMW-PAHs were dominant in soils (Masih and Taneja, 2006). LMW-PAHs were also dominant in soils from mountain areas of Canada, southeast areas of the TPC, and the Qinghai-Tibetan plateau (Choi et al., 2009; Wang et al., 2013; Yang et al., 2013). Since LMW-PAHs that have greater volatility usually occur in the vapor phase and travel more easily to remote areas by LRAT, the relatively great accumulation of LMW-PAHs in surface soils of mountains was likely due to preferential removal of compounds of larger molecular mass, during the atmospheric transport (Zhu et al., 2014; Tao et al., 2011).

\subsection{Spatial distribution of $P A H S$}

Mean concentrations of $\Sigma_{16} \mathrm{PAH}$ in soils from various parts of Nepal were in decreasing order: central region $\left(5.9 \times 10^{2} \mathrm{ng} /\right.$ $\mathrm{g} \mathrm{dm})>$ western region $\left(2.8 \times 10^{2} \mathrm{ng} / \mathrm{g} \mathrm{dm}\right)>$ far-western region $\left(1.2 \times 10^{2} \mathrm{ng} / \mathrm{g} \mathrm{dm}\right)>$ mid-western region $\left(7.0 \times 10^{1} \mathrm{ng} / \mathrm{g} \mathrm{dm}\right)$ $(p<0.05)$ (Fig. S1). Concentrations of LMW-PAHs (Fig. 2A), 4-ring PAHs (Fig. 2B), and HMW-PAHs (Fig. 2C) had the same trend with those of $\Sigma_{16} \mathrm{PAH}$ in the soils from Nepal. In Nepal, the greatest concentration of $\Sigma_{16}$ PAHs $\left(1.5 \times 10^{3} \mathrm{ng} / \mathrm{g} \mathrm{dm}\right)$ was found in soil collected from forestland near Kathmandu (Fig. 2D). Since fresh liquid fuels (petrogenic sources) release larger amounts of LMW-PAHs during combustion (Aichner et al., 2007), greater concentrations of LMW-PAHs in
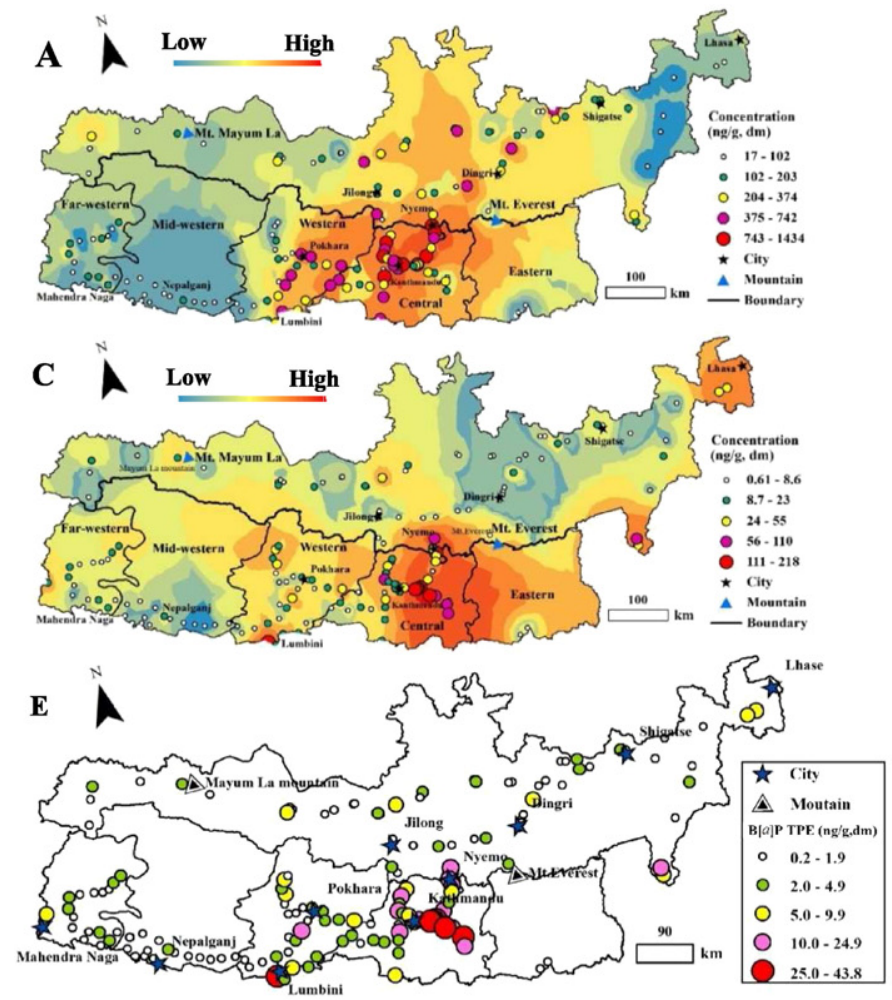

soils from central Nepal, especially around Kathmandu, imply that PAHs in this area might have originated from vehicle emissions. Greater concentrations of 4-ring PAHs and HMW-PAHs in soils from central Nepal indicated that emissions of PAHs occurred from industries and via combustion of biomass (Aichner et al., 2007). Furthermore, the mean concentration of HMW-PAHs in soils from Central Nepal (50 ng/ $\mathrm{g} \mathrm{dm}$ ) was relatively high, which might indicate that local sources of PAHs were in Kathmandu (Fig. S1). The second-greatest mean concentration of $\Sigma_{16}$ PAHs was found in western Nepal, where Pokhara, the second largest city with busy traffic and dense population, is located. Concentrations of $\Sigma_{16} \mathrm{PAHs}$ in soils from the far-western mountain areas of Nepal were greater than those from the mid-western area. Based on trajectories of masses of air in Nepal and the TPC (Fig. S2), nearly $80 \%$ of air mass originated from north India in ten years. It indicates that PAHs in the far-western area might originate from air masses crossing north India, which was demonstrated by Sharma et al. (2007). Long-distance transport of air masses from northern India was responsible for the greater concentrations of LMW-PAHs in soils from the midwestern area of Nepal.

In the TPC, the greatest concentration of $\Sigma_{16}$ PAHs $\left(1.6 \times 10^{3} \mathrm{ng} /\right.$ g dm) (Table 2) was found at Zhangmu Port in Nyemo county (Fig. 2D), which is the largest trading port connecting China with the Indian subcontinent. Concentrations of PAHs in soils from the western area to Jilong on the TPC were relatively small (Fig. 2A, B, C, D). However, relatively great concentrations of LMW-PAHs were observed in soils from the eastern area to Jilong, especially Nyemo, Shigatse, and Lhasa (Fig. 2A). Relatively great concentrations of 4-ring PAHs and HMWPAHs were observed in soils near Lhasa (Fig. 2B, C). In the western area to Jilong, no obvious local sources of PAHs were found. This result suggested that PAHs found in this area had originated from LRAT. Volatile LMW-PAHs and 4-ring PAHs, which were driven by the Indian monsoon (Wang et al., 2008), traveled through the valleys of the Himalayas (Fig. S2) and were cold-trapped in soils from higher altitude areas such as Nyemo and Shigatse in the TPC (Fig. 2A, B). Relatively great concentrations of HMW-PAHs in soils from Lhasa suggested that the primary
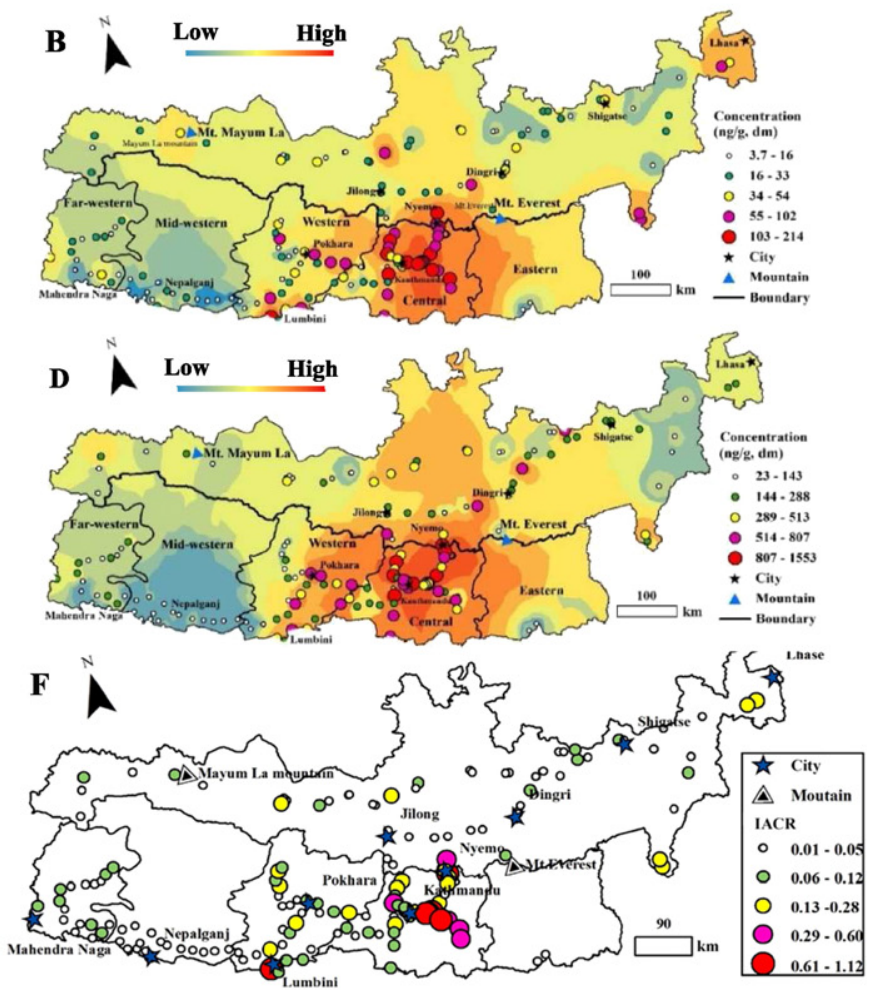

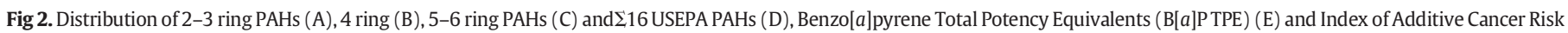
(IACR) (F) in surface soils from the Central Himalayas. 
source of PAHs was local emissions. This conclusion is supported by the fact that Lhasa city has the largest population, and, therefore, it has great emission of PAHs on the TPC (Liu et al., 2013).

\subsection{Factors influencing the spatial distribution of PAH concentrations in soils from the Central Himalayas}

Significant linear regressions were observed between concentrations of all LMW-PAHs (NAP, ACP, ANT, PHE, FLT and PYR) and $\mathrm{PAHs}$ in the mountain soils and altitude $(p<0.05)$ (Fig. 3), while concentrations of 4-ring and HMW-PAHs exhibited poor correlations with altitude (not shown here) $(p>0.05)$. Concentrations of some LMP-PAHs (Acel, Ace, Phe and Ant), 4-ring PAHs (Flu and Pyr) and इPAHs in soils around Mt. Qomolangma, China, which is located in our study area, were also positively correlated with increasing altitude (Wang et al., 2007). However, concentrations of Phe and Flu and $\mathrm{EPAHs}$ in soils at Mt. Sagarmatha, Himalayas, which is also positioned in the northeastern region of Nepal within our study area, were inversely proportional to altitude (Guzzella et al., 2011). Generally, the main input of PAHs to mountain soils is from deposition from atmosphere (Wang et al., 2007; Wang et al., 2013). Therefore, a main reason for different relationships between concentrations of PAHs in mountain soils with latitude might be distance from sources of emissions of PAHs to air in the study area. Based on trajectories of masses of air (Fig. S2), distance from cities such as New Delhi (main emission sources of PAHs) which were mainly influenced by the Westerlies in northern India to the subarea studied (Fig. 1) was obviously longer than that from counties and cities such as Nyemo and Jilong in China, Kathmandu and Pokhara in Nepal, which were the primary sources of PAHs. The transport of contaminants was influenced mostly by Indian Monsoons that transported masses of air to the study area of Wang et al. (2007), while the study area of Guzzella et al. (2011) is nearer to local sources of PAHs. There is an inverse relationship between molecular masses of PAH congeners and distance transported (Wang et al., 2007; Zhu et al., 2014). Consequently, more species of LMW-PAHs which were significantly correlated with altitude were deposited to soils in our selected subarea than those observed by Wang et al. (2007). The positive relationships between concentrations of $\mathrm{EPAH}$ and latitude observed in the present study and those observed by Wang et al. (2007) were due to the dominant proportion of LMW-PAHs to $\mathrm{\Sigma}$ PAHs ( $>80 \%$ ) in soils (Table 1). However, the negative relationship between concentrations of $\mathrm{\Sigma PAHs}$ in soils and latitude reported by Guzzella et al. (2011) was caused by the dominant proportion of $\Sigma$ PAHs being 4-5 ring PAHs.
TOC plays a significant role in adsorption of PAHs to soil and is a predictor of concentrations of PAHs in soils (Tang et al., 2005). In the present study, TOC was positively but weakly correlated with LMW-PAHs $\left(\mathrm{R}^{2}=0.11, p=0.001\right)$, 4-ring PAHs $\left(\mathrm{R}^{2}=0.10, p=0.001\right)$, HMWPAHs $\left(\mathrm{R}^{2}=0.16, p=0.001\right)$ and $\mathrm{EPAHs}\left(\mathrm{R}^{2}=0.13, p=0.001\right)$ (Fig. 4). This result indicates that at least in the area studied, on the basis of equilibrium adsorption between TOC and PAHs, TOC plays little role in spatial distributions of PAHs, sequestration or degradation of PAHs in surface soils (Hinga, 2003; Jiang et al., 2009; Nam et al., 2009). Black carbon (BC) is a sub-fraction of TOC in soil. Since BC was, under certain conditions a better descriptor of $\mathrm{PAH}$ air-soil partitioning than TOC (Ribes et al., 2003b; Bucheli et al., 2004), investigation of BC in soils would be better way to unveil PAHs in soils in the future.

Distributions of populations of humans play important role in determining the spatial distribution of PAHs. Population density is greater in Nepal than in the TP study area (Luo et al., 2016). Areas in the Himalayas at altitudes higher than $3.0 \times 10^{3} \mathrm{~m}$ are largely unpopulated (Loewen et al., 2005). The distribution of human population (Luo et al., 2016) partly explained the pattern of distributions of PAHs in soils (Fig. 2D). Influences of densities of population of humans and soil organic carbon (SOC) (and black carbon) on soil PAHs have been referred to as either source (population) or sink (SOC) related factors (Nam et al., 2009). In fact, profiles of relative concentration of PAHs in the environment were not always conserved from their origins or during their transport processing (Galarneau, 2008). Various weathering processes influence, photochemical degradation and other secondary processes of PAHs might have changed concentrations and distribution of PAHs in soils of the present study (Marynowski et al., 2011; Górka et al., 2014; Vane et al., 2014).

\subsection{Assessment of sources}

Characteristic ratios of relative concentrations of individual PAHs are widely used to determine likely origins of PAHs in various environmental media. In particular, diagnostic ratios of IcdP/(IcdP + BghiP) and FLT/ (FLT + PYR) can be applied to identify possible sources of PAHs (Yunker et al., 2002). In this study, the ratio of IcdP/(IcdP + BghiP) in surface soils from the Central Himalayas ranged from 0.04 to 0.90 (Fig. S3). Approximately $70 \%$ of samples of surface soil from the Central Himalayas had IcdP/(IcdP + BghiP) ratios ranging between 0.20 and 0.50 . Therefore, PAHs observed in those soils likely originated from combustion of fossil fuels. Ratios of FLT/(FLT + PYR) in soils ranged from 0.39 to 0.75 , and $95 \%$ of soils had ratios larger than 0.5 , which suggested that
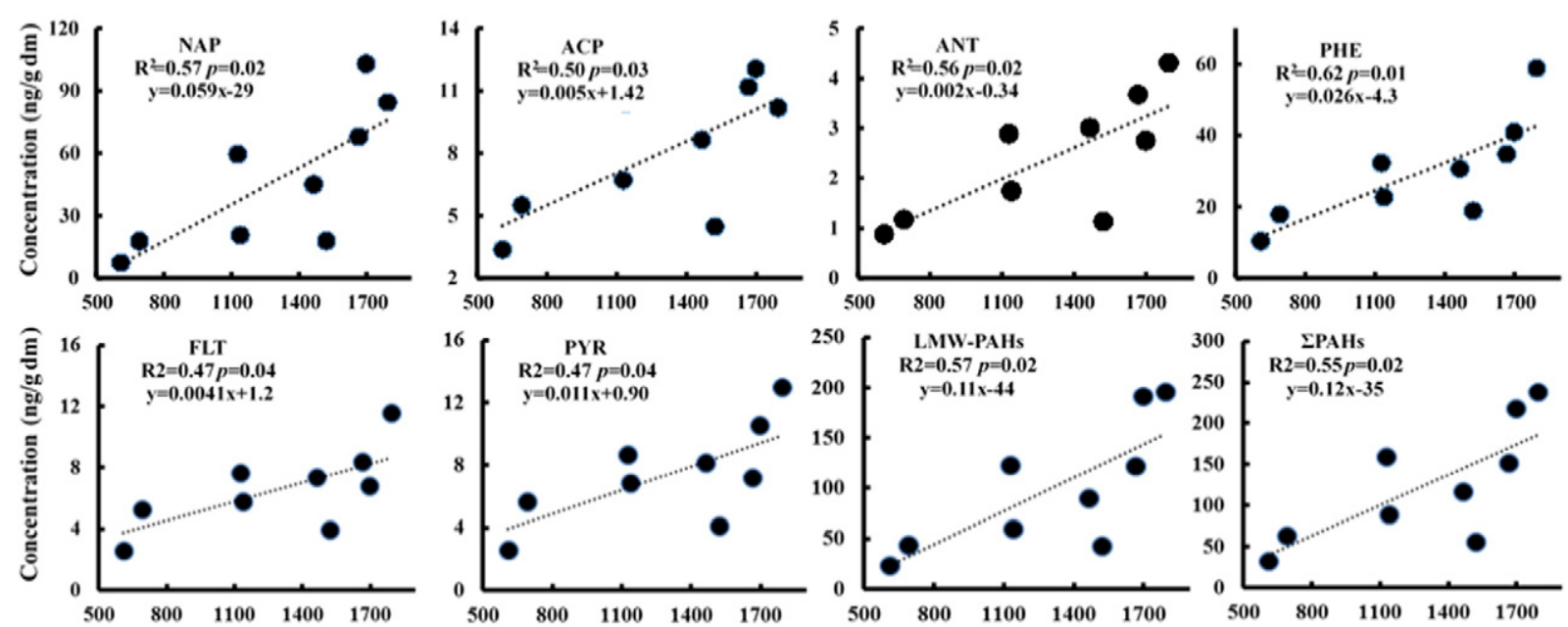

Altitude (m)

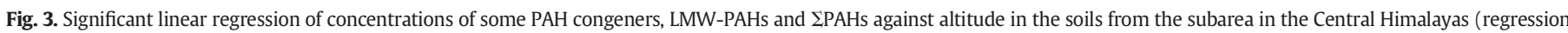
slope $t$-test, $\alpha=0.05)$. $\mathrm{R}^{2}$ : Coefficient of determination; $p$ : Probability. 

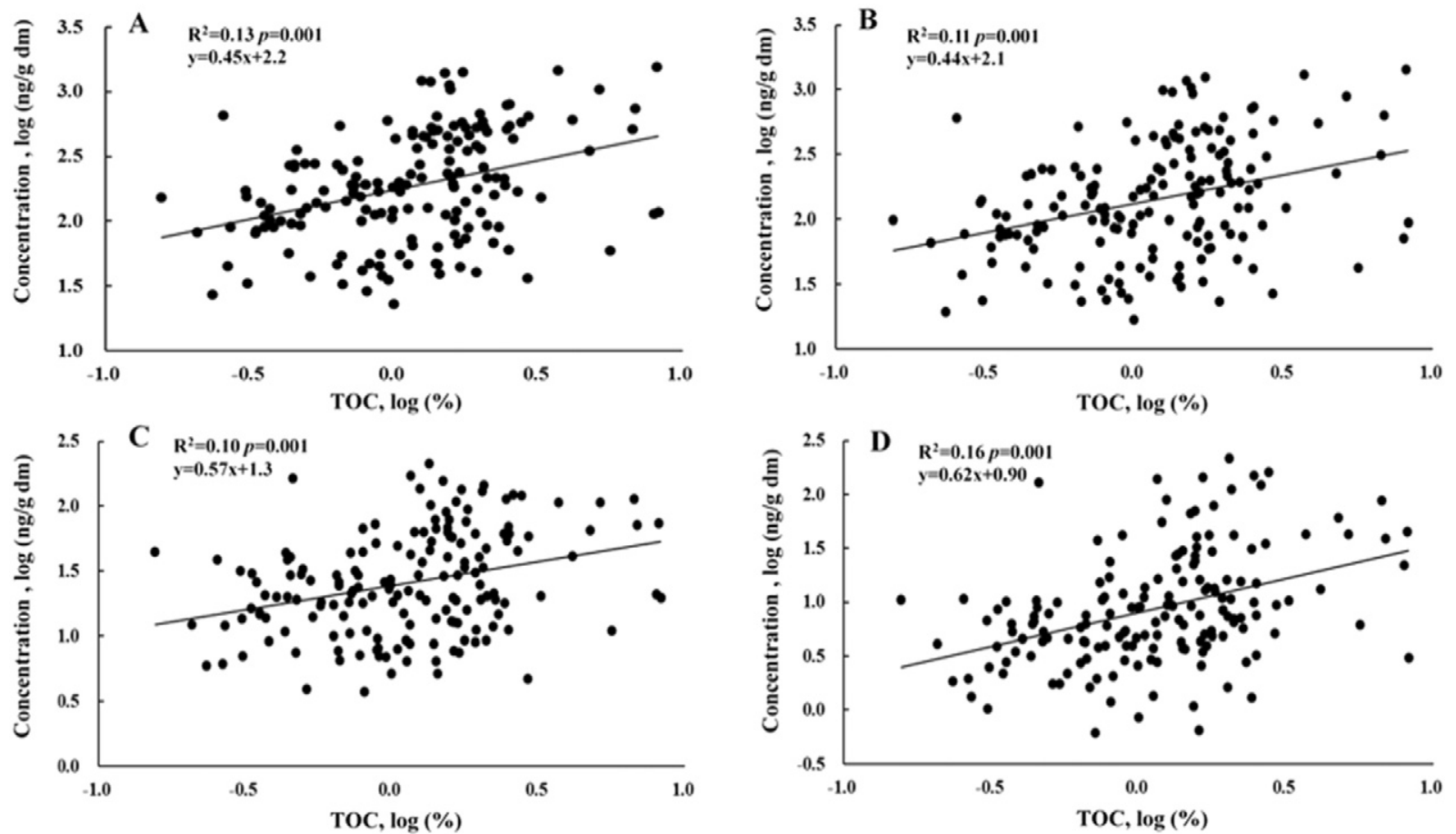

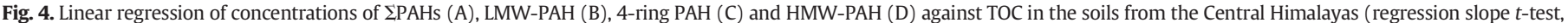
$\alpha=0.05)$. $\mathrm{R}^{2}$ : Coefficient of determination; $p$ : Probability.

combustion of biomass and coal was the primary source of PAHs in soils (Fig. S3). Therefore, values of diagnostic ratios of IcdP/(IcdP + BghiP) and FLT/(FLT + PYR) indicated that sources of PAHs in soils collected during the present study were primarily due to combustion of coal, biomass, and petroleum hydrocarbons.

Several potential sources of PAHs were identified by use of PMF (Fig. 5). Factor 1 was predominantly loaded on ANT and moderately weighted by ACY, ACP, PHE, FLT, and PYR (Fig. 5B). ANT, PHE, FLT, and

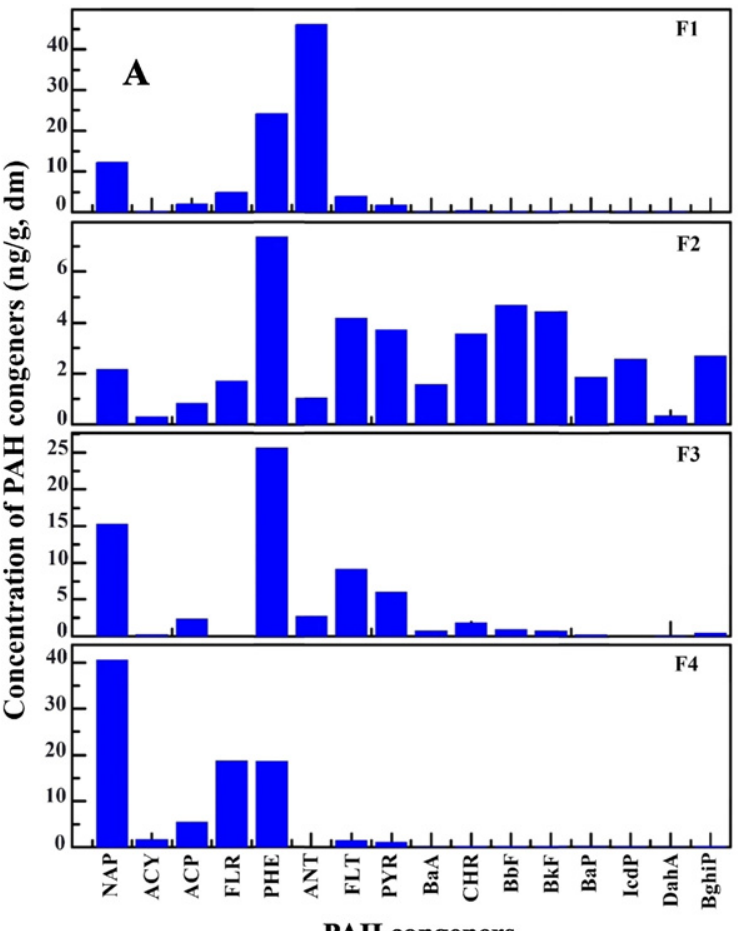

PYR are the markers for combustion of coal (Harrison et al., 1996; Larsen and Baker, 2003). Therefore, factor 1 represents combustion of coal. Factor 2 was predominately loaded on $\mathrm{BaA}, \mathrm{CHR}, \mathrm{BbF}, \mathrm{BkF}, \mathrm{BaP}$, IcdP, DahA, and BghiP (Fig. 5B). Pyrogenic PAHs are characterized by a greater proportion of $>4$-ring PAHs (Aichner et al., 2007). BghiP, BbF, and $\mathrm{BkF}$ are indicative of emissions of exhaust from combustion of gasoline and diesel fuel in internal combustion engines (Duval and Friedlander, 1981; Harrison et al., 1996). BaA and CHR are also produced

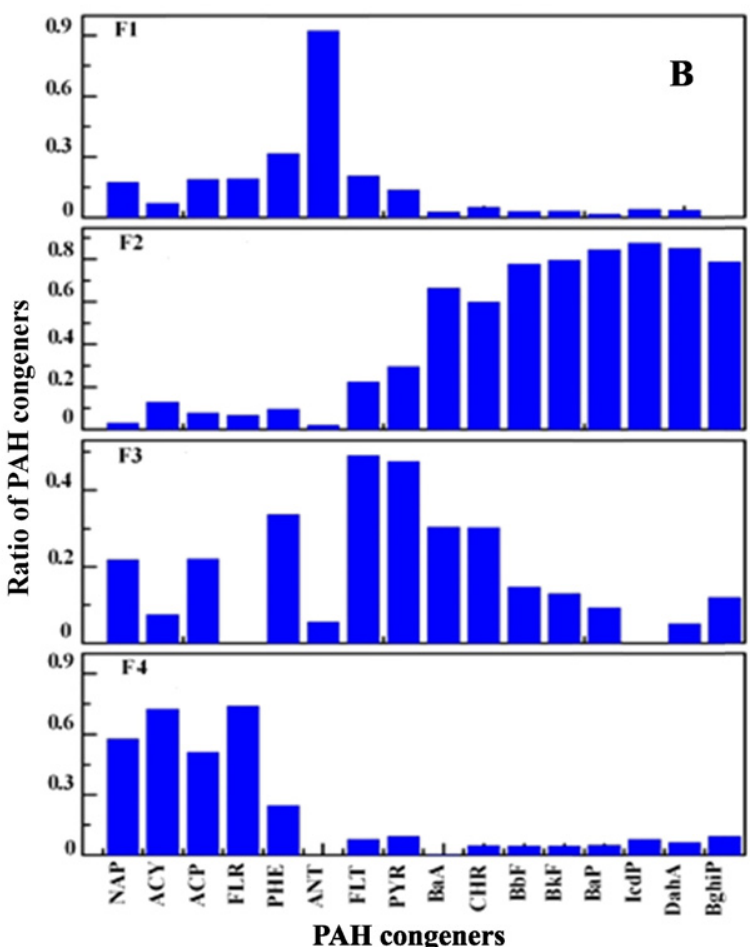


during incomplete combustion of gasoline and diesel (Lee et al., 2005). Therefore, factor 2 represented emissions from internal combustion engines. Factor 3 was dominated by FLT and PYR and moderately weighted by NAP, ACP, PHE, BaA, and CHR (Fig. 5B). Combustion of biomass (including wood) is characterized by enrichment with ANT, PHE, FLT, and PYR (Harrison et al., 1996). NAP is also produced during incomplete combustion-related sources (Simcik et al., 1999). Therefore, factor 3 represented combustion of biomass (Fig. 5B). Factor 4 was dominated by ACY and FLR and moderately weighted by NAP, ACP, and PHE. Petrogenic PAHs are characterized by a predominance of LMW-PAHs (Aichner et al., 2007). Therefore, factor 4 was designated as unburned petroleum hydrocarbons (oil) (Fig. 5B).

Mean contributions of each source to $\Sigma_{16} \mathrm{PAHs}$ in the soils as determined by the PMF analysis are shown (Fig. S4). Combustion of coal was the primary source of PAHs in soils on the TPC (42\%) (Fig. S4E), far-western Nepal (33\%) (Fig. S4A), and western Nepal (28\%) (Fig. S4C). Traffic contributed most to $\Sigma_{16} \mathrm{PAHs}$ in soils from midwestern Nepal (42\%) (Fig. S4B), whereas unburned petroleum (oil) contributed most to those in soils from central Nepal (52\%) (Fig. S4D). Relative contributions to $\Sigma_{16}$ PAHs in the soils were $33 \%$ for combustion of coal, $30 \%$ for unburned petroleum hydrocarbons (oil), $22 \%$ for combustion of biomass, and 15\% for exhaust from vehicles (Fig. S4F). Thus, PAHs in soils of all studied areas were mainly from pyrogenic origins (including unburned petroleum (oil), biomass, and coal combustion), because the sources accounted for $85 \%$ of $\Sigma_{16} \mathrm{PAHs}$ in the soils. These results are consistent with the fact that wood, petroleum, and coal constitute approximately $90 \%$ of the total energy consumption of Nepal (MOPE and SACEP, 2001).

\subsection{Risk of PAHs in soils to humans and wildlife}

Based on the 16 USEPA priority pollutants, Maliszewska-Kordybach (1996) classified magnitudes of concentrations of PAHs in soils into four categories: unpolluted (200 ng/g dm), weakly polluted (200-600 ng/ $\mathrm{g} \mathrm{dm})$, polluted $(600-1000 \mathrm{ng} / \mathrm{g} \mathrm{dm})$, and severely polluted ( $>1000 \mathrm{ng} / \mathrm{g} \mathrm{dm}$ ). According to this classification scheme, $68 \%$ of samples of soil on the TPC would be classified as unpolluted; $24 \%$, weakly polluted; $5 \%$, polluted; and $3 \%$, severely polluted with PAHs (Table 3 ). The severely polluted soils on the TPC were collected from the Zhangmu Port area. Approximately $48 \%$ of samples of soil in Nepal were unpolluted; $40 \%$, weakly polluted; $6 \%$, polluted; and $7 \%$ severely polluted with PAHs (Table 3). The soils classified as being unpolluted with PAHs were collected from far-western and western Nepal, whereas those classified as being polluted and severely polluted were collected from Pokhara and Kathmandu, respectively (Fig. 2D).
The mean concentration of B[a]P TPE in soils from Nepal (6.1 ng/ $\mathrm{g} \mathrm{dm})$ was greater than that in soils from the TPC $(3.3 \mathrm{ng} / \mathrm{g} \mathrm{dm})$ (Table 3). Carcinogenic potency of PAHs to human through direct contact with soils from Nepal was approximately twice as great as that from the TPC. Greatest concentrations of B $[a]$ P TPE were found in central Nepal, especially in areas near Kathmandu and the border between China and Nepal (Table 3 and Fig. 2E). This result suggested that the greatest carcinogenic potency in Nepal. Since no sample of soil from Nepal or the TPC had B[a]P TPE exceeding the $S G_{H H}(600 \mathrm{ng} / \mathrm{g} \mathrm{dm}$ $\mathrm{B}[\mathrm{a}] \mathrm{P}$ TPE) (Fig. 2E), PAHs in soils from the studied area were unlikely pose unacceptable risk to the local population due to direct contact.

Values of IACR for soils of the TPC ranged from 0.0067 to 0.93 , with an average of 0.078 . No sample of soil from the TPC had IACP exceeding the safe value of 1.0 set by the Canadian Council of Ministers of the Environment (CCME). The IACR values for the soils from Nepal ranged from 0.092 to 1.1 , with an average value of 0.14 (Table 3). Only one sample of soil from the study area had an IACR greater than the safe value (Fig. 2F). This indicates that leaching of carcinogenic PAHs from all soils except one posed no unacceptable risk to potable water in the Central Himalayas.

SQGs of 14 PAHs were proposed based on the non-carcinogenic effects of PAHs by the CCME (Table 2) (Wang et al., 2015). The SQGs for agriculture were adopted because agricultural land predominated in the present study area. Concentrations of 12 PAHs (NAP and PHE were excluded from the 14 PAHs mentioned above) were less than their corresponding SQGs. In all, the SQG values of NAP and PHE for agriculture use were exceeded by $1 \%$ and $27 \%$ of the soils, respectively. In the present study, $39 \%$ of samples had an $\mathrm{m}-\mathrm{RQ}$ value of $<1$, suggesting de minimis risk caused by PAHs at these sites, whereas $61 \%$ of the samples had an $\mathrm{m}-\mathrm{RQ}$ value of $<0.1$, indicating negligible risk. This result suggested that in $39 \%$ of the samples PAHs might pose a slight risk to wildlife and the environment of the Central Himalayas.

\section{Conclusions}

The mean concentration of PAHs in soils of the southern side of the Central Himalayas, Nepal $\left(3.3 \times 10^{2} \mathrm{ng} / \mathrm{g} \mathrm{dm}\right)$ was significantly greater than that on the TPC at the northern side $\left(2.4 \times 10^{2} \mathrm{ng} / \mathrm{g} \mathrm{dm}\right)$. Soils from the central and western regions of Nepal, especially the areas around Kathmandu and Pokhara had relatively great concentrations of PAHs, compared with those from the southern side of the Central Himalayas. On the other hand, soils form the eastern area to Jilong, especially Nyemo, Shigatse, and Lhasa on the TPC, had relatively great concentrations of PAHs, compared with those from the north side of the Central Himalayas. $13 \%$ of samples of soil from Nepal and $8 \%$ from the TPC

Table 3

Statistics of PAH pollution levels, carcinogenic risk and risk for potable water in the Central Himalayas.

\begin{tabular}{|c|c|c|c|c|c|c|c|c|}
\hline \multirow[t]{2}{*}{ Pollution level } & \multirow{2}{*}{$\frac{\text { Central Nepal }}{\text { No. }^{\text {a }}}$} & \multirow{2}{*}{$\frac{\text { Far-western Nepal }}{\text { No. }}$} & \multirow{2}{*}{$\frac{\text { Mid-western Nepal }}{\text { No. }}$} & \multirow{2}{*}{$\frac{\text { Western Nepal }}{\text { No. }}$} & \multicolumn{2}{|c|}{ Nepal } & \multicolumn{2}{|c|}{ Tibetan Plateau, China } \\
\hline & & & & & No. & Abundance (\%) & No. & Abundance (\%) \\
\hline Unpolluted & 3 & 15 & 17 & 12 & 47 & 48 & 45 & 68 \\
\hline Weakly polluted & 24 & 2 & 0 & 12 & 38 & 39 & 16 & 24 \\
\hline Polluted & 3 & 0 & 0 & 3 & 6 & 6 & 3 & 5 \\
\hline Severely polluted & 7 & 0 & 0 & 0 & 6 & 7 & 2 & 3 \\
\hline
\end{tabular}

\begin{tabular}{|c|c|c|c|c|c|c|c|c|c|c|c|c|}
\hline \multicolumn{13}{|c|}{ Carcinogenic risk } \\
\hline & Min-Max & Mean & Min-Max & Mean & Min-Max & Mean & Min-Max & Mean & Min-Max & Mean & Min-Max & Mean \\
\hline $\begin{array}{l}\mathrm{B}[a] \mathrm{P} \text { TPE } \\
\quad(\mathrm{ng} / \mathrm{g} \mathrm{dm})\end{array}$ & $0.96-44$ & 12 & $0.60-7.3$ & 2.0 & $0.24-2.1$ & 1.0 & $0.49-34$ & 4.5 & $0.24-44$ & 6.1 & $0.26-23$ & 3.3 \\
\hline
\end{tabular}

\begin{tabular}{|c|c|c|c|c|c|c|c|c|c|c|c|c|}
\hline Risk for potable water & & & & & & & & & & & & \\
\hline & Min-Max & Mean & Min-Max & Mean & Min-Max & Mean & Min-Max & Mean & Min-Max & Mean & Min-Max & Mean \\
\hline Index of Additive Cancer Risk (IACR) & $0.097-1.1$ & 0.25 & $0.019-0.13$ & 0.053 & $0.0092-0.068$ & 0.032 & $0.017-0.73$ & 0.10 & $0.0092-1.1$ & 0.14 & $0.0067-0.93$ & 0.078 \\
\hline
\end{tabular}


were polluted by PAHs with concentrations $>600 \mathrm{ng} / \mathrm{g} \mathrm{dm}$. LMW-PAHs (2-3-ring PAHs), especially PHE, NAP, and ANT, were predominant PAHs in the soils from the entire study area. Concentrations of $\Sigma$ PAHs in mountain soils were positively but weakly correlated with altitude. High altitude and shorter distance from emission source were mainly responsible for great concentrations of PAHs in soils from Central Himalayas. TOC in soil was poorly correlated with PAHs, suggesting the little role of TOC in adsorption of PAHs in mountain soils of the Central Himalayas. Approximately $85 \%$ of PAH sources in the soils of the Central Himalayas were from pyrogenic origins, among which $33 \%$ were from combustion of coal, $30 \%$, from unburned petroleum hydrocarbons and $22 \%$, from combustion of biomass. Based on the calculated $\mathrm{B}[a] \mathrm{P}$ TPE, PAHs in almost all soils were unlikely to pose a risk to the local residents due to direct contact, whereas the leaching of PAHs from the soils would have no risk to local potable water. The calculated $\mathrm{m}-\mathrm{RQ}$ values indicated that $39 \%$ of the samples of soil posed a low risk to wildlife and the environment of the Central Himalayas.

\section{Acknowledgments}

This study was supported by the Strategic Priority Research Program of the Chinese Academy of Sciences (grant no. XDB03030504) and the National Natural Science Foundation of China (grant nos. 41271502 and 41571479). Prof. Giesy received support from the program of 2012 "Great Level Foreign Experts" (\#GDT20143200016) funded by the State Administration of Foreign Experts Affairs, P.R. China to Nanjing University and the Einstein Professor Program of the Chinese Academy of Sciences. He was also supported by the Canada Research Chair program. Prof. de Boer received support from the Chinese 1000-talent plan for foreign experts.

\section{Appendix A. Supplementary data}

Supplementary data to this article can be found online at http://dx. doi.org/10.1016/j.scitotenv.2016.03.006.

\section{References}

Agarwal, T., Khillare, P.S.V., Shridhar, V., Ray, S., 2009. Pattern, sources and toxic potential of PAHs in the agricultural soils of Delhi, India. J. Hazard. Mater. 163 (2-3), 1033-1039.

Aichner, B., Glaser, B., Zech, W., 2007. Polycyclic aromatic hydrocarbons and polychlorinated biphenyls in urban soils from Kathmandu, Nepal. Org. Geochem. 38, 700-715.

Bortey-Sam, N., Ikenaka, Y., Nakayama, S.M., Akoto, O., Yohannes, Y.B., Baidoo, E., Mizukawa, H., Ishizuka, M., 2014. Occurrence, distribution, sources and toxic potential of polycyclic aromatic hydrocarbons (PAHs) in surface soils from the Kumasi Metropolis, Ghana. Sci. Total Environ. 496, 471-478.

Bucheli, T.D., Blum, F., Desaules, A., Gustafsson, Ö., 2004. Polycyclic aromatic hydrocarbons, black carbon, and molecular markers in soils of Switzerland. Chemosphere $56,1061-1076$

Chen, P., Kang, S., Li, C., Rupakheti, M., Yan, F., Li, Q., Ji, Z., Zhang, Q., Luo, W., Sillanpää, M., 2015. Characteristics and sources of polycyclic aromatic hydrocarbons in atmospheric aerosols in the Kathmandu Valley, Nepal. Sci. Total Environ. 538, 86-92.

Choi, S.D., Shunthirasingham, C., Daly, G.L., Xiao, H., Lei, Y.D., Wania, F., 2009. Levels of polycyclic aromatic hydrocarbons in Canadian mountain air and soil are controlled by proximity to roads. Environ. Pollut. 157, 3199-3206.

Dalla Valle, M., Jurado, E., Dachs, J., Sweetman, A.J., Jones, K.C., 2005. The maximum reservoir capacity of soils for persistent organic pollutants: implications for global cycling. Environ. Pollut. 134, 153-164.

Duval, M., Friedlander, S., 1981. Source resolution of polycyclic aromatic hydrocarbons in the Los Angeles atmosphere application of a CMB with first-order decay. US EPA Report EPA-600/2-81-161. US Government Printing Office, Washington, DC, USA

Fernández, P., Grimalt, J.O., Vilanova, R.M., 2002. Atmospheric gas-particle partitioning of polycyclic aromatic hydrocarbons in high mountain regions of Europe. Environ. Sci. Technol. 36, 1162-1168.

Galarneau, E., 2008. Source specificity and atmospheric processing of airborne PAHs: implications for source apportionment. Atmos. Environ. 42, 8139-8149.

Górka, M., Rybicki, M., Simoneit, B.R.T., Marynowski, L., 2014. Determination of multiple organic matter sources in aerosol PM $_{10}$ from Wrocław, Poland using molecular and stable carbon isotope compositions. Atmos. Environ. 89, 739-748.

Guzzella, L., Poma, G., De Paolis, A., Roscioli, C., Viviano, G., 2011. Organic persistent toxic substances in soils, waters and sediments along an altitudinal gradient at Mt. Sagarmatha, Himalayas, Nepal. Environ. Pollut. 159, 2552-2564.
Harrison, R.M., Smith, D., Luhana, L., 1996. Source apportionment of atmospheric polycyclic aromatic hydrocarbons collected from an urban location in Birmingham, UK. Environ. Sci. Technol. 30, 825-832.

Hinga, K., 2003. Degradation rates of low molecular weight PAH correlate with sediment TOC in marine subtidal sediments. Mar. Pollut. Bull. 46 (4), 466-474.

Jiang, Y.F., Wang, X.T., Wang, F., Jia, Y., Wu, M.H., Sheng, G.Y., Fu, J.M., 2009. Levels, composition profiles and sources of polycyclic aromatic hydrocarbons in urban soil of Shanghai, China. Chemosphere 75, 1112-1118.

Kumar, B., Verma, V.K., Kumar, S., Sharma, C.S., 2013. Probabilistic health risk assessment of polycyclic aromatic hydrocarbons and polychlorinated biphenyls in urban soils from a tropical city of India. J. Environ. Sci. Health A Tox. Hazard. Subst. Environ. Eng. 48, 1253-1263.

Larsen, R.K., Baker, J.E., 2003. Source apportionment of polycyclic aromatic hydrocarbons in the urban atmosphere: a comparison of three methods. Environ. Sci. Technol. 37, 1873-1881.

Lee, R.G., Coleman, P., Jones, J.L., Jones, K.C., Lohmann, R., 2005. Emission factors and importance of PCDD/Fs, PCBs, PCNs, PAHs and PM10 from the domestic burning of coal and wood in the UK. Environ. Sci. Technol. 39, 1436-1447.

Li, Y.T., Li, F.B., Chen, J.J., Yang, G.Y., Wan, H.F., Zhang, T.B., Zeng, X.D., Liu, J.M., 2008. The concentrations, distribution and sources of PAHs in agricultural soils and vegetables from Shunde, Guangdong, China. Environ. Monit. Assess. 139, 61-76.

Li, Q., Wang, N., Wu, X., Pu, J., He, J., Zhang, C., 2011. Sources and distribution of polycyclic aromatic hydrocarbons of different glaciers over the Tibetan Plateau. Sci. China Earth Sci. 54, 1189-1198.

Liu, J., Li, J., Lin, T., Liu, D., Xu, Y., Chaemfa, C., Qi, S., Liu, F., Zhang, G., 2013. Diurnal and nocturnal variations of PAHs in the Lhasa atmosphere, Tibetan plateau: implication for local sources and the impact of atmospheric degradation processing. Atmos. Res. $124,34-43$.

Loewen, M.D., Sharma, S., Tomy, G., Wang, F., Bullock, P., Wania, F., 2005. Persistent organic pollutants and mercury in the Himalaya. Aquatic Ecosystem Health 8, 223-233.

Luo, W., Gao, J., Bi, X., Xu, L., Guo, J., Zhang, Q., Romesh, K.Y., Giesy, J.P., Kang, S., 2016. Identification of sources of polycyclic aromatic hydrocarbons based on concentrations in soils from two sides of the Himalayas between China and Nepal. Environ. Pollut. 212, 424-432.

Maliszewska-Kordybach, B., 1996. Polycyclic aromatic hydrocarbons in agricultural soils in Poland: preliminary proposals for criteria to evaluate the level of soil contamination. Appl. Geochem. 11, 121-127.

Marynowski, L., Kurkiewicz, S., Rakociński, M., Simoneit, B.R.T., 2011. Effects of weathering on organic matter: I. Changes in molecular composition of extractable organic compounds caused by paleoweathering of a Lower Carboniferous (Tournaisian) marine black shale. Chem. Geol. 285, 144-156.

Masih, A., Taneja, A., 2006. Polycyclic aromatic hydrocarbons (PAHs) concentrations and related carcinogenic potencies in soil at a semi-arid region of India. Chemosphere $65,449-456$.

McCready, S., Birch, G.F., Long, E.R., Spyrakis, G., Greely, C.R., 2006. Relationships between toxicity and concentrations of chemical contaminants in sediments from Sydney Harbour, Australia, and vicinity. Environ. Monit. Assess. 120 (1-3), 187-220.

MOPE, I., SACEP, N., 2001. UNEP (2001). State of the Environment, Nepal.

Nam, J.J., Sweetman, A.J., Jones, K.C., 2009. Polynuclear aromatic hydrocarbons (PAHs) in global background soils. J. Environ. Monit. 11, 45-48.

Quiroz, R., Grimalt, J.O., Fernandez, P., Camarero, L., Catalan, J., Stuchlik, E., Thies, H., Nickus, U., 2010. Polycyclic aromatic hydrocarbons in soils from European high mountain areas. Water Air Soil Pollut. 215, 655-666.

Ribes, A., Grimalt, J.O., Garcia, C., Cuevas, E., 2003a. Polycyclic aromatic hydrocarbons in mountain soils of the subtropical Atlantic. J. Environ. Qual. 32, 977-987.

Ribes, S., Van Drooge, B., Dachs, J., Gustafsson, Ö., Grimalt, J.O., 2003b. Influence of soot carbon on the soil-air partitioning of polycyclic aromatic hydrocarbons. Environ. Sci. Technol. 37, 2675-2680.

Sharma, H., Jain, V.K., Khan, Z.H., 2007. Characterization and source identification of polycyclic aromatic hydrocarbons (PAHs) in the urban environment of Delhi. Chemosphere 66, 302-310.

Simcik, M.F., Eisenreich, S.J., Lioy, P.J., 1999. Source apportionment and source/sink relationships of PAHs in the coastal atmosphere of Chicago and Lake Michigan. Atmos. Environ. 33, 5071-5079.

Tang, L.L., Tang, X.Y., Zhu, Y.G., 2005. Contamination of polycyclic aromatic hydrocarbons (PAHs) in urban soils in Beijing, China. Environ. Int. 31, 822-828.

Tao, S., Wang, W., Liu, W., Zuo, Q., Wang, X., Wang, R., Wang, B., Shen, G., Yang, Y., He, J.S., 2011. Polycyclic aromatic hydrocarbons and organochlorine pesticides in surface soils from the Qinghai-Tibetan plateau. J. Environ. Monit. 13, 175-181.

Tsai, P.J., Shih, T.S., Chen, H.L., Lee, W.J., Lai, C.H., Liou, S.H., 2004. Assessing and predicting the exposures of polycyclic aromatic hydrocarbons (PAHs) and their carcinogenic potencies from vehicle engine exhausts to highway toll station workers. Atmos. Environ. 38, 333-343.

Vane, C.H., Kim, A.W., Beriro, D.J., Cave, M.R., Knights, K., Moss-Hayes, V., Nathanail, P.C., 2014. Polycyclic aromatic hydrocarbons (PAH) and polychlorinated biphenyls (PCB) in urban soils of Greater London, UK. Appl. Geochem. 51, 303-314.

Vives, I., Grimalt, J.O., Fernandez, P., Rosseland, B., 2004. Polycyclic aromatic hydrocarbons in fish from remote and high mountain lakes in Europe and Greenland. Sci. Total Environ. 324, 67-77.

Wang, X., Yao, T., Cong, Z., Yan, X., Kang, S., Zhang, Y., 2007. Concentration level and distribution of polycyclic aromatic hydrocarbons in soil and grass around Mt. Qomolangma, China. Chin. Sci. Bull. 52, 1405-1413.

Wang, X.P., Yao, T.D., Wang, P.L., Wei, Y., Tian, L.D., 2008. The recent deposition of persistent organic pollutants and mercury to the Dasuopu glacier, Mt. Xixiabangma, central Himalayas. Sci. Total Environ. 394, 134-143. 
Wang, X., Yang, H., Gong, P., Zhao, X., Wu, G., Turner, S., Yao, T., 2010. One century sedimentary records of polycyclic aromatic hydrocarbons, mercury and trace elements in the Qinghai Lake, Tibetan Plateau. Environ. Pollut. 158, 3065-3070.

Wang, S., Ni, H.G., Sun, J.L., Jing, X., He, J.S., Zeng, H., 2013. Polycyclic aromatic hydrocarbons in soils from the Tibetan plateau, China: distribution and influence of environmental factors. Env. Sci. Process. Impact 15, 661.

Wang, C., Wang, X.P., Gong, P., Yao, T.D., 2014. Polycyclic aromatic hydrocarbons in surface soil across the Tibetan Plateau: spatial distribution, source and air-soil exchange. Environ. Pollut. 184, 138-144

Wang, X.T., Chen, L., Wang, X.K., Lei, B.L., Sun, Y.F., Zhou, J., Wu, M.H., 2015. Occurrence, sources and health risk assessment of polycyclic aromatic hydrocarbons in urban (Pudong) and suburban soils from Shanghai in China. Chemosphere 119, 1224-1232.

Wania, F., Westgate, J.N., 2008. On the mechanism of mountain cold-trapping of organic chemicals. Environ. Sci. Technol. 42, 9092-9098.

Wild, S.R., Jones, K.C., 1995. Polynuclear aromatic hydrocarbons in the United Kingdom environment: a preliminary source inventory and budget. Environ. Pollut. 88, 91-108.

Xu, S., Liu, W., Tao, S., 2006. Emission of polycyclic aromatic hydrocarbons in China. Environ. Sci. Technol. 40, 702-708.
Yang, S., Gao, D., Li, B., 1987. A preliminary study on the moisture trajectory in the downstream region of Yarlung Zangbo River. Sci. China, Ser. B, Chem. 8, 893-902.

Yang, R., Zhang, S., Li, A., Jiang, G., Jing, C., 2013. Altitudinal and spatial signature of persistent organic pollutants in soil, lichen, conifer needles, and bark of the southeast Tibetan Plateau: implications for sources and environmental cycling. Environ. Sci. Technol. 47, 12736-12743.

Yunker, M.B., Macdonald, R.W., Vingarzan, R., Mitchell, R.H., Goyette, D., Sylvestre, S., 2002. PAHs in the Fraser River basin: a critical appraisal of PAH ratios as indicators of PAH source and composition. Org. Geochem. 33, 489-515.

Zhang, Y., Tao, S., 2009. Global atmospheric emission inventory of polycyclic aromatic hydrocarbons (PAHs) for 2004. Atmos. Environ. 43, 812-819.

Zhao, X., Kim, S.K., Zhu, W., Kannan, N., Li, D., 2015. Long-range atmospheric transport and the distribution of polycyclic aromatic hydrocarbons in Changbai Mountain. Chemosphere 119, 289-294.

Zhu, N., Schramm, K.W., Wang, T., Henkelmann, B., Zheng, X., Fu, J., Gao, Y., Wang, Y., Jiang, G., 2014. Environmental fate and behavior of persistent organic pollutants in Shergyla Mountain, southeast of the Tibetan Plateau of China. Environ. Pollut. 191, 166-174. 